\title{
Heterosis and reciprocal effects for growth traits in crosses of New Zealand White, Dutch and Chinchilla breeds of rabbits.
}

\author{
S. N. Ibe*, V. N. Obasi, G. S. Ojewola and E. N. Nwachukwu \\ Department of Non-Ruminant Animal Production Michael Okpara University of Agriculture, \\ Umudike, P.M.B. 7267 Umuahia, Abia State, Nigeria. \\ *Corresponding Author: e-mail:sylvester_ibe@yahoo.com
}

\section{Abstract}

Records of body weight (BW) and linear body measurements (LBMs), namely body lenglh (BL), body width (BWH), heart girth $(H G)$, height-at-withers (HW), shoulder-to-tail drop (ST), ear length (EL). head-to-shoulder (HS), length of fore limb (LFL), length of hind limb (LHL) and head circumference (HC) taken on 72 kits produced through complete diallel crosses were used to estimate heterosis and reciprocal effects. The crosses involved New Zealand White (NZW), Dutch (DT) and Chinchilla $(C H)$ breeds of rabbits. Only NZW $\times$ DT and $C H \times D T$ crosses showed positive heterosis for $B W$, indicating that non-additive effects of genes could be important for this trait. Results for the LBMs were generally similar. Reciprocal effect was not significant $(P>0.05)$ for all trails, suggesting that any of the breeds may be used as sire or dam in planned crossbreeding programmes.

Key words: Rabbit, heterosis, reciprocal effect, growth traits

\section{Introduction}

Exploitation of heterosis is the major reason for crossbreeding. Heterosis has been exploited to genetically improve characters that are subject to little additive gene action, such as those related to fitness (Ndjon and Nwakalor, 1999).

Working with Bauscat, Giza White, White Flander and Baladi Red rabbits and their crosses in complete diallel matings, $\Lambda$ fin et al. (1987) observed positive heterosis for birth weight in all crosses, except in White Flander x Giza White. Afifi et al. (1973) had reported positive heterosis for kit birth weight in all possible crosses of three breeds of rabbits. Niedzwiadek (1979) reported that Californian $x$ New Zealand White crossbreds reached $2.5 \mathrm{~kg}$ body weight three days earlier and had better feed conversion ratios than purebreds. Similar results were obtained by Brun and Ouhagoun (1989) and Ozimba and Lukefahr (1991). Oetting et al. (1989) observed that their main cross involving New Zealand White and Japanese White was significantly heavier at birth, at weaning and post-wcaning than the purebreds. Fayeye and Ayorinde (2000) reported that heterosis was best manifested for litter traits in New Zealand White $\mathrm{x}$ Chinchilla crossbreds. However, Lukefahr et 
al. (1983), Brun and Ouhagoun (1989), Ouhagoun (1978) and Carregal and Lui (1984) reported low heterotic effect for rate of preweaning gain in different crosses.

Reciprocal effect could also be exploited in crosses. Fayeye and Ayorinde (2000) observed that reciprocal effect was important for a number of litter traits and that this was higher in New Zealand White $x$ Californian than in New Zealand White $\mathrm{x}$ Chinchilla and Californian $\mathrm{x}$ Chinchilla. Similar results were reported by Lebas et al. (1986) and Emsley et al. (1980). Reciprocal effects have also been reported for sexual maturity and mature body weight in poultry (Emsley et al., 1980) and for post-weaning growth and carcass characteristics in cattle (Johnston et al., 1992).

The objective of this study was to evaluatc heterotic and reciprocal effects on body weight and linear body measurements in crosses involving New Zealand White, Dutch and Chinchilla breeds of domestic rabibits in a rainforest zone. Available information reviewed herein has largely been on litter characteristics in crosses involving different breeds of rabbits under temperate or sub-tropical humid environments.

\section{Materials and methods}

\section{Location of study}

This study was carried out at the Rabbitry Unit of Michael Okpara University of Agriculture, Umudike. The University is located at longitude $7^{\circ} 292$ East and latitude $5^{\circ} 212$ North on an elevation of about $120 \mathrm{~m}$ above sea level. Umudike falls within the rainforest zone of Nigeria, with an average annual rainfall of about $1220 \mathrm{~mm}$ distributed over eight months (March to November) with its peak in June and July and dry spell usually in August. It has a humid climate and temperature that ranges from $28^{\circ} \mathrm{C}$ in the wet season to slightly over $35^{\circ} \mathrm{C}$ in the dry season.

\section{Matings and experimental animals}

Three breeds of rabbits were used in this study. namely New Zealand White (NZW), Dutch (DT) and Chinchilla $(\mathrm{CH})$. Progeny of crosses were produced in two parities.

The matings were as follows:

Pure crosses: NZW x NZW; DT x DT; $\mathrm{CH} \times \mathrm{CH}$ Main crosses: NZW $\times$ DT; NZW $\times$ CH; DT $\times$ CH Reciprocal crosses: DT x NZW; CH x NZW; CH x DT

One buck of each breed was mated to three does, one each of the three breeds, randomly sampled from the population maintained in the farm. Seventy-two kits were produced from the crosses, with 35 and 37 kits in the first and second parities, respcctively. The distribution of kits was as follows: NZW x NZW (9), NZW x DT (7), NZW $x$ CH (7), DT x DT (10), DT x NZW (9), DT x $\mathrm{CH}(8), \mathrm{CH} \times \mathrm{CH}(8), \mathrm{CH} \times \mathrm{NZW}(7)$ and $\mathrm{CH} \times$ DT (7).

The does were flushed for one week and were served immediately thereafter. Does were taken to each buck in his cage for mating between the hours of 9.00 and $11.00 \mathrm{am}$. After a successful mating, the does were removed and new ones brought in. This procedure was repeated three consecutive times. Thereafter, the bucks were left alone in their individual cages in case of failure and also for the second parity matings.

\section{Management of experimental animals}

The rabbits were fed with compounded feed and forage (grass and legumes) between the hours of 8.00 and 9.00 am and 4.00 and $5.00 \mathrm{pm}$. Water was given ad libitum. The does were flushed with concentrate and forage during the gestation period in order to provide enough nutrients for embryonic and foetal development. Does were diagnosed for pregnancy and those diagnosed 
open were immediately returned to the appropriate buck for another service.

One week to the expected date of kindling, one wooden kindling box was washed, disinfected and provided for each doe in her cage. This was to cnable the does get used to them before kindling. After kindling, the kits were examined and dead ones were removed from the boxes. Kindling boxes were removed when the kits were five weeks old.

\section{Parameters measured}

The parameters measured were body weight (BWT), body length (BL), body width (BWH), heart girth (HG), height-at-withers (HW), shoulder-to-tail drop (ST), ear length (EL), headto-shoulder (HS), length of forelimb (LFL), length of hind limb (LHL) and head circumference (HC). All the parameters, with the exception of body weight $(\mathrm{g})$, were measured in $\mathrm{cm}$, using a tailor's tape. Body weight was measured using a sensitive table weighing scale.

\section{Statistical analysis}

Data obtained on all parameters were adjusted for fixed effects, namely parity and age, by using the derived additive constant in expression (1).

$$
\text { where } \quad \begin{aligned}
& \mathrm{C}_{i}=-\left(\mathrm{P}_{\mathrm{i}}+\mathrm{A}_{\mathrm{i}}\right) \\
& \mathrm{C}_{\mathrm{i}}=\text { adjustment factor } \\
& \mathrm{P}_{\mathrm{i}}=\text { Least-squares constant for parity, } \\
& \text { and } \\
& \mathrm{A}_{j}=\text { I cast-squares constant for agc. }
\end{aligned}
$$

The appropriate value of the adjustment factor was added to each observed value. For example, to adjust data in the first parity and second week, the adjustment factor consisted of -(Leastsquares constant for parity $1+$ Least-squares constant for week 2), etc.

Direct heterosis for each cross was estimated with the method of linear contrasts as outlined by Dickerson (1992), as follows:

Direct heterosis for each cross $=$ Mean of the cross - Mean of parental purebreds...
This was computed for both main and reciprocal crosses.

Pcrcentage heterosis was obtained, also separately for main and reciprocal crosses, as a quotient between direct heterosis (Expression 2) and mean purebred value multiplied by 100 , as follows:

Percentage heterosis $=$

$$
\frac{\text { Dircct heterosis }}{\text { Mean of purebreds }} \times \frac{100}{1} \quad \ldots(3)
$$

The combined heterotic effect of each set of main and reciprocal crosses was also computed as the average of the heterosis of the main and reciprocal crosses.

Expression (4) was used to estimate reciprocal effects, according to Griffing (1956).

Reciprocal effect, $r_{i j}=1 / 2\left(X_{i j}-X_{i j}\right) \quad \ldots(4)$ where $X_{i j}$ and $X_{i i}$ are observed values of each parameter in the $\mathrm{ij}^{\text {th }}$ (main) cross and the $\mathrm{ji}^{\text {th }}$ (reciprocal) cross, respectively.

Griffing (1956) also gave expression for Analysis of variance sum of squares for testing the significance of reciprocal effects as

$$
\mathrm{SS}_{\mathrm{r}}=1 / 2 \mathrm{O} \dot{\mathrm{O}}<\mathrm{j}\left(\mathrm{X}_{\mathrm{ij}}-\mathrm{X}_{\mathrm{ji}}\right)^{2}
$$

with degree of freedom, $p(p-1) / 2$, where $p=$ number of breeds crossed.

\section{Results and Discussion}

\section{Heterosis}

Table I gives cstimates of direct and percentage heterosis in both main and reciprocal crosses. Only New Zealand White (NZW) x Dutch (DT) and Chinchilla (C.H) $\times$ DT crosses showed positive heterosis for body weight. The increase in body weight as a resuit of the crossbreeding was 5.0 and $5.81 \%$ for NZW $x$ DT and $\mathrm{CH} x$ $D T$, respectively. This indicates that, for these two crosses, non-additive effects of genes could be exploited, through crossbreeding, to bring 


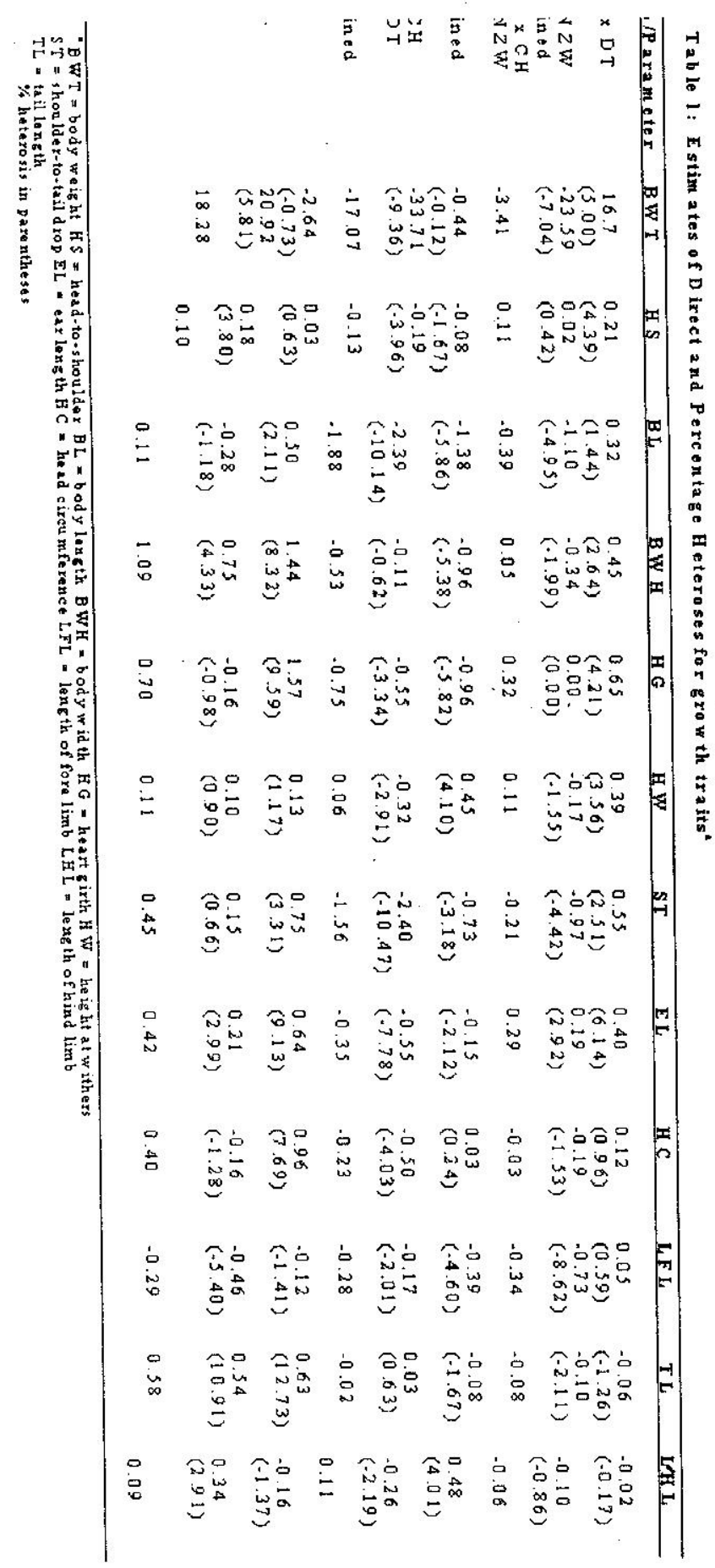


about genetic improvement for body weight. This contradicts existing knowledge that body weight and conformation traits in farm animals are generally highly heritable, implying that rapid genetic improvement could be brought about by seiection and exploitation of additive effects of genes, rather than crossbreeding. The result obtained in this study could be due to maternal cffect of DT, since the reciprocal crosses, DT $x$ N\%W and DT $x$ CH yielded negative heterosis for body weight.

- . - - ... $\div-$ ( positive heterosis) for Californian $-1-1$ White crossbreds than for the parental purcbreds. Brun and Ouhagoun (1989) had earlier reported a similar result with the same cross. Khan and Lukefahr (1996) reported positive heterosis of $10.5 \%$ for post-weaning litter weight. Fayeye and Ayorinde (2000) observed positive heterosis for kit weight from birth to 21 days post-partum ranging between 1.4 and $49.32 \%$. Other authors (Afifi et al., 1987; Oetting et al., 1989; Nicdzwiadek, 1979) also reported positive heterosis for body weight at different ages.

The other crosses, namely DT x NZW, NZW x $\mathrm{CH}, \mathrm{CH} \times \mathrm{NZW}$ and $\mathrm{DT} \times \mathrm{CH}$, gave negative heteroses for body weight of $(-) 7.04,(-) 0.12$, (19.36 and $(-) 0.73 \%$, respectively. As stated earlier, this situation is cxpected and indicates that, for these crosses, additive effects of genes could best be exploited, through selective breeding, for rapid genetic improvement in body veight. Heterosis could subsequently be exploited by crossing different lines that had been improved by within-line selection. Medellin and Lukefahr (2001) reported negative heterosis of $1-19.3 \%$ for market weight in rabbits.

Results for the linear body measurements ( $L B M S$ ) were generally similar to those for body weight. Whereas $\mathrm{NZW} \times$ DT, DT $\times \mathrm{CH}$ and $\mathrm{CH}$ $x$ DT crossbreds showed positive heterosis for most of the LBMs, DT x NZW, NZW x CH and $\mathrm{CH} \times \mathrm{NZW}$ crossbreds had negative estimates for most of the LBMs. The implication of these results is as earlier explained for body weight. However, the positive heteroses obtained for some LBMs could not be explained on the basis of maternal effects, as was the case with body weight, since the observed heterotic effect was shown by crosses involving different breeds of dam. Chineke et al. (2002) reported that their New Zealand White x Dutch-belted crossbred recorded best performance in heart girth, height at withers and body length at pre-weaning ages of 7 and 21 days and at post-weaning age of 56 days.

\section{Reciprocal effects}

Estimates of reciprocal effects are presented in Table 2. Reciprocal effect was not significant $(\mathrm{P}>0.05)$ for BWT and for all LBMs. This suggests that any of the breeds may be used as sire or dam in planned crossbreeding programmes. However, the large positive reciprocal effects for body weight in NZW $\times$ DT/ D' $x$ NZW (20.175) and in NZW x CH/CH $x$ NZW (16.635) suggest some advantage of using NZW as sire for crossbreeding with DT and $\mathrm{CH}$. On the other hand, the large negative effect (11.78 ) for the same trait in DT $\times \mathrm{CH} / \mathrm{CH} \times \mathrm{DT}$ gives an indication that $\mathrm{CH}$ could be better as sire in a crossbreeding programme with DT.

Fayeye and Ayorinde (2000) reported that reciprocal effects were important for rate of body weight increase and litter and kit weight gains, among other traits, in three crossbred groups. They suggested that reciprocal effects could be exploited where heterosis has failed.

\section{Conclusion}

There was positive heterosis for body weight and linear body measurements in NZW $x$ DT and 